\title{
Sensitivity of Holocene East Antarctic productivity to subdecadal variability set by sea ice
}

\author{
Katelyn M. Johnson ${ }^{1,2} \bowtie$, Robert M. McKay2 , Johan Etourneau ${ }^{3,4,5}$, Francisco J. Jiménez-Espejo ${ }^{\text {3,6, }}$, \\ Anya Albot ${ }^{2}$, Christina R. Riesselman ${ }^{7}$ 7,8, Nancy A. N. Bertler ${ }^{10}{ }^{1,2}$, Huw J. Horgan ${ }^{2}$, Xavier Crosta ${ }^{5}{ }^{5}$, \\ James Bendle $\mathbb{\circledR}^{9}$, Kate E. Ashley ${ }^{9}$, Masako Yamane ${ }^{10}{ }^{10}$, Yusuke Yokoyama ${ }^{11}{ }^{11}$, Stephen F. Pekar ${ }^{12}$, \\ Carlota Escutia $\mathbb{1 0}^{3}$ and Robert B. Dunbar ${ }^{13}$
}

\begin{abstract}
Antarctic sea-ice extent, primary productivity and ocean circulation represent interconnected systems that form important components of the global carbon cycle. Subdecadal to centennial-scale variability can influence the characteristics and interactions of these systems, but observational records are too short to evaluate the impacts of this variability over longer timescales. Here, we use a 170-m-long sediment core collected from Integrated Ocean Drilling Program Site U1357B, offshore Adélie Land, East Antarctica to disentangle the impacts of sea ice and subdecadal climate variability on phytoplankton bloom frequency over the last $\sim 11,400$ years. We apply X-ray computed tomography, Ice Proxy for the Southern Ocean with 25 carbon atoms, diatom, physical property and geochemical analyses to the core, which contains an annually resolved, continuously laminated archive of phytoplankton bloom events. Bloom events occurred annually to biennially through most of the Holocene, but became less frequent ( $\sim 2-7$ years) at $\sim 4.5 \mathrm{ka}$ when coastal sea ice intensified. We propose that coastal sea-ice intensification subdued annual sea-ice break-out, causing an increased sensitivity of sea-ice dynamics to subdecadal climate modes, leading to a subdecadal frequency of bloom events. Our data suggest that projected loss of coastal sea ice will impact the influence of subdecadal variability on Antarctic margin primary productivity, altering food webs and carbon-cycling processes at seasonal timescales.
\end{abstract}

A ntarctica's marine margin is a complex biological and oceanographic system in which sea-ice growth, Antarctic Bottom Water (AABW) formation and high primary productivity act as a significant $\mathrm{CO}_{2}$ sink and ventilate the Southern Ocean ${ }^{1,2}$. High primary productivity occurs where nutrients are brought to the surface, including oceanographic fronts ${ }^{3}$, polynyas ${ }^{4}$, upwelling near the continental shelf break ${ }^{5}$ and the marginal ice zone (MIZ) all of which are influenced by Antarctic wind fields. High productivity and export events around Antarctica occur with changing insolation and stratification associated with sea-ice break-up ${ }^{7}$. Large-scale subdecadal climate modes, specifically the El NiñoSouthern Oscillation (ENSO), Southern Annular Mode (SAM) and Indian Ocean Dipole (IOD), are known to affect sea ice ${ }^{8,9}$ and wind fields ${ }^{10}$ around Antarctica. The teleconnection between ENSO (which varies at 2-7 year periods) and Antarctic sea-ice variability is largely driven by wind changes resulting from hemispheric-scale sea level pressure and 500 mbar height anomalies ${ }^{8}$. This teleconnection can be amplified or dampened by other subdecadal climate modes such as the IOD and SAM ${ }^{9-12}$. Collectively, these subdecadal climate modes alter meridional and zonal wind flows ${ }^{9,10}$ that regulate sea-ice break-out ${ }^{11}$ at 2-7 year periods, thus influencing primary productivity in Antarctica ${ }^{13-15}$. Clarifying how the annual cycle and subdecadal-scale climate modes have impacted past Antarctic coastal systems will inform models used to project future system response ${ }^{16}$.
We investigate a $170 \mathrm{~m}$ sediment core recovered from the Adélie Basin (Integrated Ocean Drilling Program (IODP) Site U1357B) ${ }^{17}$ along the Wilkes Land margin of East Antarctica (Fig. 1). The Adélie Basin is a region of high primary productivity near the MIZ. It also lies beneath and downstream of several large polynya systems and the westward-flowing Antarctic Coastal Current. The drill site targeted a high-sedimentation $(\sim 1.5-2 \mathrm{~cm}$ per year $) \mathrm{drift}$ deposit (Adélie Drift) dominated by pelagic biogenic deposition. It provides an ultra-high-resolution Holocene record of climate and oceanographic variability adjacent to the Mertz Polynya system, one of the largest exporters of sea ice and AABW along the East Antarctic margin ${ }^{2}$. Previously collected Antarctic cores have significantly lower sedimentation rates, and alternate between massive (bioturbated) and laminated diatom ooze $\mathrm{e}^{18,19}$. They cannot resolve high-frequency change at subdecadal scales. However, U1357B is continuously laminated, and high sedimentation rates afford an unprecedented opportunity to assess subdecadal and annual changes at the Antarctic oceanic margin.

An ultra-high-resolution record of marine biogenic blooms The east-west elongated Adélie Drift deposit formed parallel to the wind-driven Antarctic Coastal Current ${ }^{2,20}$. This current influences both surface and deep waters on the continental shelf ${ }^{2,20}$. Consequently, the mass accumulation rate (MAR) (Methods) in this drift is thought to reflect current strength, and only partially

'GNS Science, Lower Hutt, New Zealand. ${ }^{2}$ Antarctic Research Centre, Victoria University of Wellington, Wellington, New Zealand. ${ }^{3}$ Andaluz Institute of Earth Sciences, CSIC-University of Granada, Granada, Spain. ${ }^{4}$ EPHE, PSL University, Paris, France. ${ }^{5}$ UMR 5805 EPOC CNRS, University of Bordeaux, Bordeaux, France. ${ }^{6}$ Biogeochemistry Center, JAMSTEC, Yokosuka, Japan. ${ }^{7}$ Department of Geology, University of Otago, Dunedin, New Zealand. ${ }^{8}$ Department of Marine Science, University of Otago, Dunedin, New Zealand. ${ }^{9}$ School of Geography, Earth, and Environmental Sciences, University of Birmingham, Birmingham, UK. ${ }^{10}$ Institute for Space-Earth Environmental Research (ISEE), Nagoya University, Nagoya, Japan. ${ }^{11}$ Analytical Center for Environmental Study, Atmosphere and Ocean Research Institute, University of Tokyo, Kashiwa, Japan. ${ }^{12}$ School of Earth and Environmental Sciences, City University of New York - Queens College, New York, NY, USA. ${ }^{13}$ School of Earth, Energy, and Environmental Sciences, Stanford University, Stanford, CA, USA. $\bigotimes_{e}$-mail: k.johnson@gns.cri.nz 
a

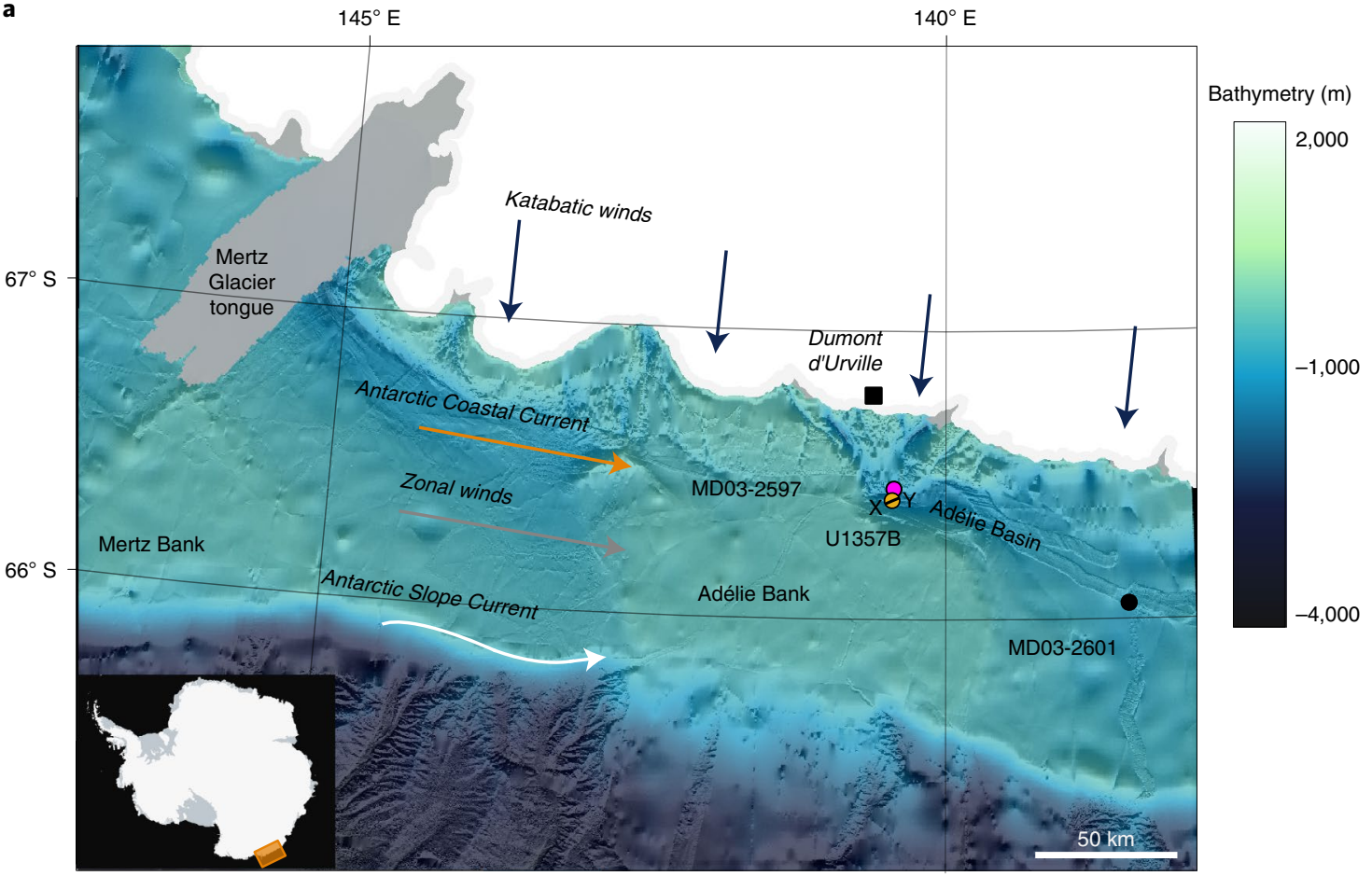

b

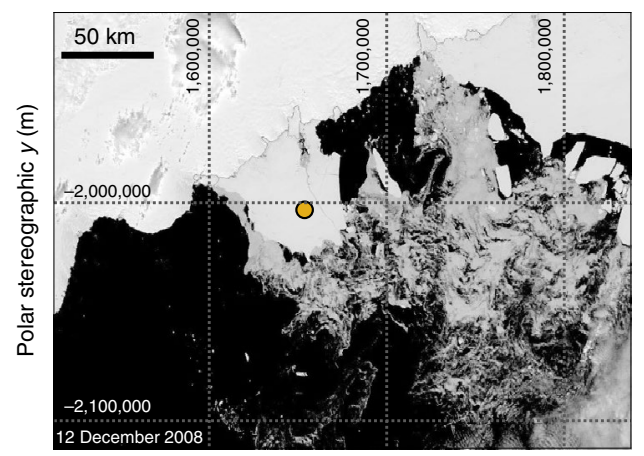

C

Polar stereographic $x(m)$

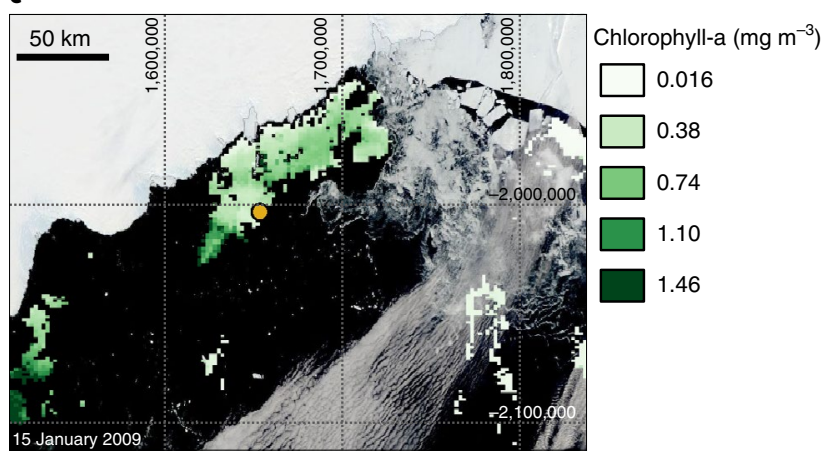

Fig. 1 | Area of study and example bloom event after sea-ice break-out. a, Map ${ }^{46-48}$ of Adélie Land and locations of U1357B (orange circle), MD03-2601 (black circle) and MD03-2597 (pink circle) sites and Dumont d'Urville (DDU) station (black square). Primary bathymetric features ${ }^{48}$, wind directions and current locations are indicated. $X-Y$ (black) indicates approximate location of seismic profile ${ }^{17}$ in Fig. 2. b, Moderate Resolution Imaging Spectroradiometer (MODIS) true colour (bands 1, 4 and 3) satellite imagery capturing sea-ice break-out on 12 December 2008. c, MODIS true colour (bands 1, 4 and 3) satellite imagery overlaid with chlorophyll-a concentrations ${ }^{49,50}$ from phytoplankton bloom event on 15 January 2009 , following sea-ice break-out. Site U1357B is indicated by orange circle in $\mathbf{b}$ and $\mathbf{c}$. Antarctic polar stereographic projection (EPSG: 3031). MODIS true-colour satellite images from NASA Worldview.

reflects changes in biological productivity (Fig. 2). Comparison of the covarying siliciclastic (detrital) and biogenic $\mathrm{MAR}^{21}$ (Fig. 3c) suggests that detrital and biogenic sediments are advected to the site together, under the influence of wind-driven currents and focused into the Adélie Basin by shelf bathymetry (Fig. 2). Nearby core MD03-2601 (Fig. 1) shows sedimentation rates covarying with $\mathrm{U} 1357 \mathrm{~B}$ throughout the Holocene, indicating that the sediment advection process is a regional signal (Fig. 2 and Extended Data Fig. 1).

Iceberg rafted debris (IRD) is negligible (Extended Data Fig. 2), aside from the very bottom of the core $(>168 \mathrm{~m}$ below sea floor (mbsf)) suggesting that direct sediment supply from icebergs is limited. The geometry and location of the drift are inconsistent with deposition as part of a glaciomarine fan system. Regional bathymetric highs are characterized by poorly sorted diamicts and muddy sands ${ }^{22}$. Grain size frequency distributions in those settings indicate the partial winnowing of the $<125 \mu \mathrm{m}$ component by bottom currents ${ }^{22}$. However, detrital siliciclastic material in the bathymetric troughs, including the Adélie Drift deposit, are consistently $<125 \mu \mathrm{m}$ with a well-defined silt-fine sand mode (Extended Data Fig. 2). This is interpreted as representing suspension settling of winnowed muds derived from diamicts on adjacent highs, suggesting that the primary control on sedimentation is from current strength and sediment advection (Fig. 2). As suspended sediment winnowed from the banks is advected towards U1357, settling of sediment will occur where current slows as it passes over deep bathymetric troughs ${ }^{22}$. Therefore, U1357 represents a sediment trap and changes in sediment grain size are a function of Antarctic Coastal Current strength, with larger grain sizes transported during stronger currents $\mathrm{s}^{22}$. This is supported by the covariance of sand 


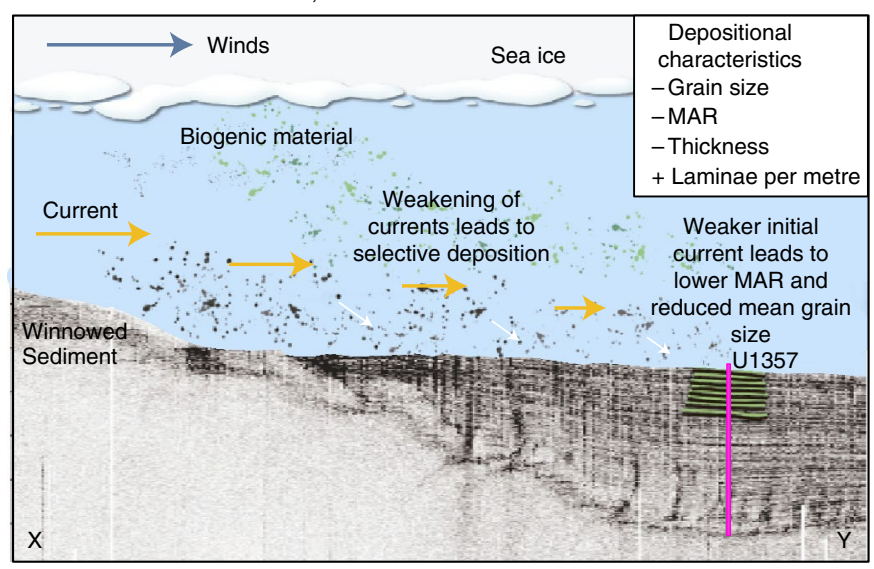

b

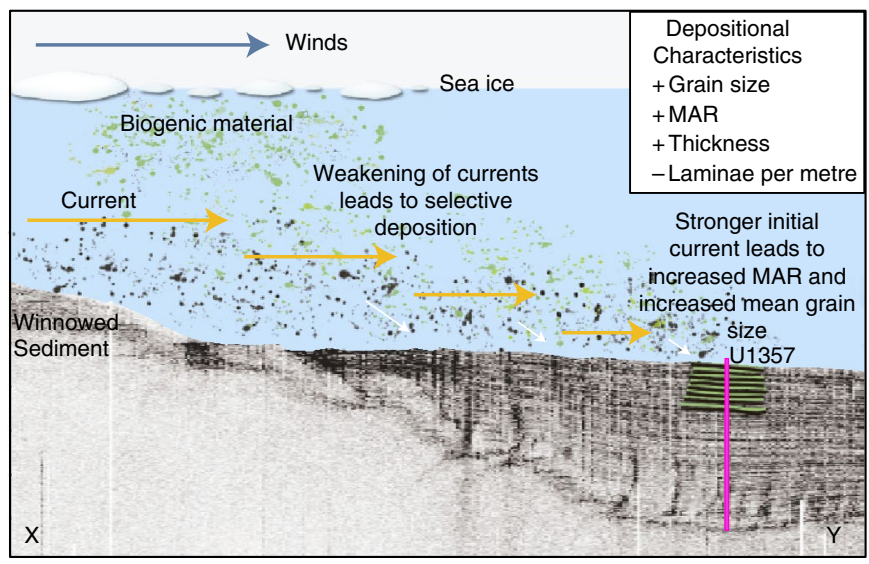

Fig. 2 | Simplified sediment deposition model for U1357B. a, Simplified deposition model of Adélie Drift during weaker winds (katabatic/zonal; blue arrows), more sea ice and subsequent weaker coastal current (yellow arrows). Biogenic and winnowed terrigenous material are selectively deposited (white arrows) into drift as water slows over basin. Light and dark laminae indicated by brown and green lines. Pink line indicates approximate location of U1357. Relative strength of winds and currents indicated by arrow size. Characteristics of this mode are reduced grain size, reduced $M A R$, reduced laminae thickness and increased laminae per metre. $X$, $Y$ marks seismic profile direction as seen in Fig. 1. b, same as $\mathbf{a}$, but for stronger winds (katabatic/zonal), less sea ice and stronger current.

percent with MAR curves, whereby an increase in MAR and sand percent relate to increased current speed (Fig. 3c,e and Extended Data Fig. 3).

The site also traps biogenic material produced in the Dumont d'Urville polynya above ${ }^{4}$, as well as biogenic material advected from the Mertz Polynya to the east. It is assumed that local biogenic material dominates ${ }^{17}$. Large phytoplankton bloom events along Antarctica's coastal margins are associated with a relatively fresh and stably stratified meltwater layer originating from seasonal sea-ice melt $^{4,6}$. Seasonal sea-ice break-up in this region is strongly affected by changes in katabatic and zonal wind intensity ${ }^{23}$. Diatom analysis from MD03-2597 in the Adélie Drift and nearby MD03-2601 interprets light laminae as biogenic bloom events, occurring during spring sea-ice retreat, which are rapidly exported to the seafloor ${ }^{24,25}$.

To determine light laminae frequency, the top and bottom of each light lamina bloom event were determined manually using X-ray computed tomography (CT) images and compared with greyscale time series extracted from raw CT data (Methods, Extended Data
Fig. 4 and Fig. 3a). Comparisons of the greyscale curve with gamma ray attenuation (GRA) bulk density, natural gamma radiation (NGR), X-ray fluorescence (XRF) silica and XRF titanium indicate that changes in the $\mathrm{CT}$ profile are primarily associated with changes in laminae composition (Extended Data Fig. 5). This is assessed further by independent time series analysis of the greyscale and productivity indicators in the XRF data (Fig. 4). Ice Proxy for the Southern Ocean with 25 carbon atoms ( IPSO $_{25}$ ) data from U1357B (Methods) and diatom analysis from MD03-2601(refs. ${ }^{26,27}$ ) are used to assess the influence of sea-ice conditions on sedimentology and bloom frequency. $\mathrm{IPSO}_{25}$ is interpreted as a proxy for fast ice ${ }^{28}$, sea ice anchored to features along the continental margin, whereas increases in Fragilariopsis curta relative abundance indicate cooler temperatures and later spring sea-ice melting ${ }^{27}$.

\section{Subdecadal drivers of coastal Adélie Land bloom events}

Applying the age model to the manual laminae counts, we find that annual to biennial frequencies dominate before $4.5 \mathrm{ka}$. Subdecadal periodicities (2-7 years) dominate after $4.5 \mathrm{ka}$ and are superimposed on distinct variations occurring at centennial to millennial timescales (Fig. 3d). These annual to subdecadal frequencies, as well as the lower-frequency shifts, are upheld by evolutionary spectral analysis of the raw CT-scan greyscale data and inferred XRF productivity ratio Si/Ti (Methods and Fig. 4). Comparison of these data with the MAR curve, IPSO $_{25}$ and diatom assemblage data indicate distinct climate states in the Holocene, noted in other Antarctic records (Fig. 3) ${ }^{16,29}$. From 4.5 ka, a baseline shift occurs in coastal sea-ice proxies and sand percent, which correspond with less-frequent bloom events relative to the overall record (Fig. 3 and Extended Data Fig. 6). These laminae events occur at frequencies that are consistent with modern-day ENSO frequencies of 2-7 years (Figs. 3 and 4). However, this relationship is interrupted between 0.8 and $1.8 \mathrm{ka}$, when $\mathrm{IPSO}_{25}$ is reduced and bloom events are more frequent.

Although some records argue for a baseline shift in ENSO variability at $4-5 \mathrm{ka}$ (refs. ${ }^{30,31}$ ), others suggest it has been highly variable for the past $7 \mathrm{ka}$ (ref. ${ }^{32}$ ). Given that a consistent pattern is not yet recognized in Holocene ENSO records ${ }^{31,33}$, we remain cautious about correlating Antarctic time series with low-latitude records of Holocene ENSO variance ${ }^{31,33}$. Temporally limited proxy records of other subdecadal climate modes ${ }^{34,35}$ (for example, IOD and SAM), which amplify or dampen the ENSO response along Adélie Land ${ }^{9-12}$, present a similar issue. This precludes us from making a direct comparison of how variations in the intensity of these subdecadal climate modes have impacted Adélie Land. However, there is no evidence that ENSO frequencies have shifted out of the 2-7 year band into the 1-2 year band ${ }^{30-33}$. SAM and IOD modulate the amplitude of ENSO influence on winds ${ }^{10}$ and coastal sea ice ${ }^{9,11}$, not the frequency. Below, we investigate how the frequency of biological bloom events has shifted through the Holocene. We interpret our data primarily in the context of local productivity drivers. We also identify whether bloom frequencies are consistent with modern subdecadal climate modes, which regulate sea-ice break-out ${ }^{8-10}$ and induce bloom events ${ }^{13,15}$, or the annual seasonal cycle.

\section{Local deglaciation-influenced bloom events (11.4 to $8 \mathrm{ka}$ )}

Sediments in the lowermost $\sim 0.7 \mathrm{~m}$ of U1357B are poorly sorted, with IRD visible in the CT images (Extended Data Fig. 7). Upcore, IRD is largely absent from the CT images and grain size frequency distributions (Extended Data Fig. 2). Bloom events occurred at an annual frequency around $11.4 \mathrm{ka}$, before trending towards a biennial period (5-7 laminae per 10 years) between 10.8 and 9 ka (Fig. 3d). Bloom frequency was highest at $\sim 8.2 \mathrm{ka}$, with one or multiple events occurring annually.

Before $\sim 8.2 \mathrm{ka}$, frequent occurrences of laminae peaks are attributed to freshwater pulses from the final phase of local East Antarctic 


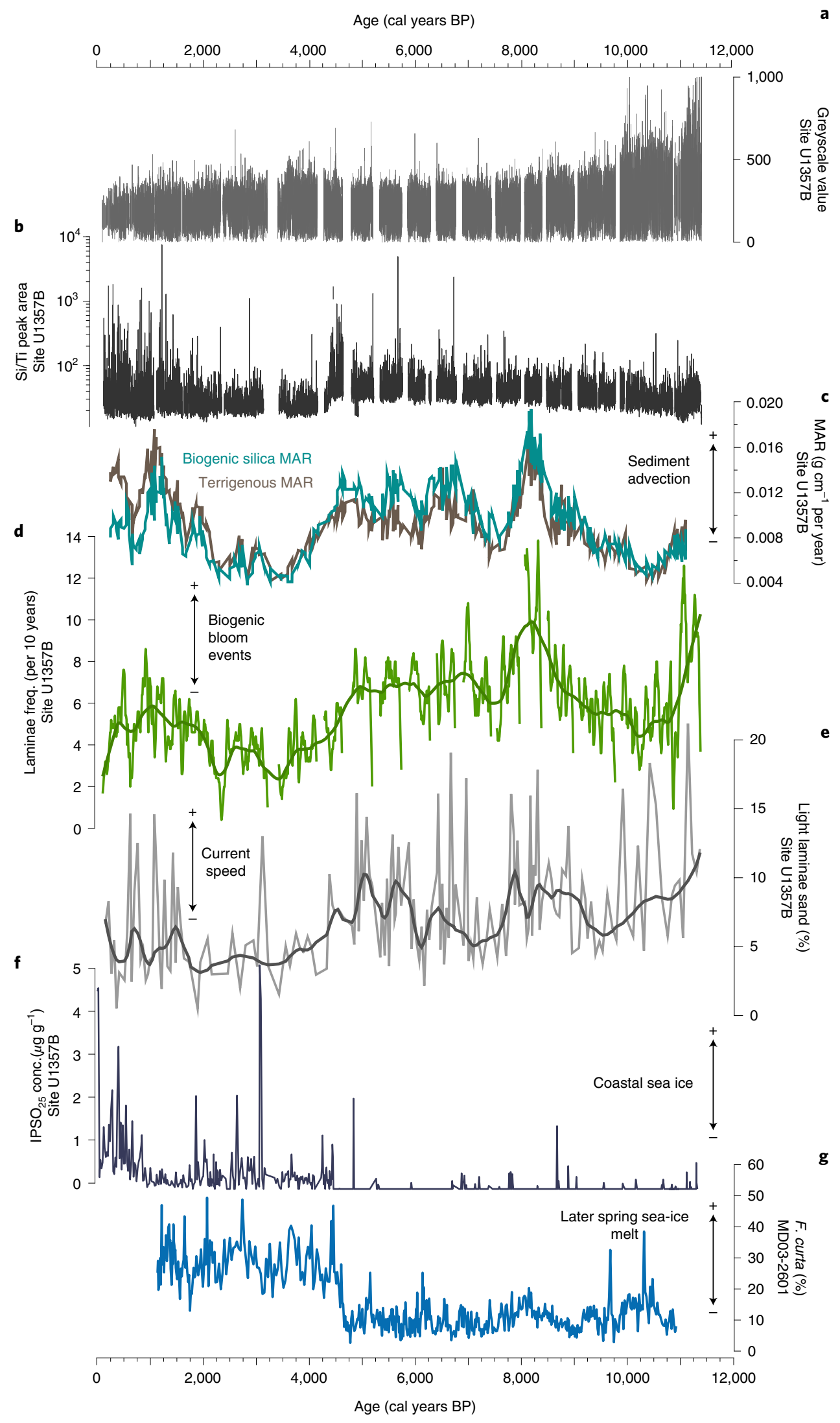

Fig. 3 Holocene proxy records in Adélie Land. a, Raw CT greyscale data. b, Raw XRF linescan data of productivity ratio Si/Ti. c, MAR from U1357B. Green is biogenic silica MAR; brown is terrigenous ${ }^{21}$. d, Laminae frequency per 10 years smoothed in a five-point moving mean; the bold curve is an rlowess smoothing, using a 5\% span of the data. e, Sand percentage of the light laminae, which is representative of current speed; the bold curve is an rlowess smoothing using a $5 \%$ span of the data. f, IPSO 25 concentration from U1357B, a proxy for fast ice conditions. g, Percentage of $F$. curta from MD03-2601 (ref. ${ }^{27}$ ), a diatom species indicative of later spring sea-ice melt. Missing data in $\mathbf{a}$ and $\mathbf{b}$ represent intervals with no core recovery. 


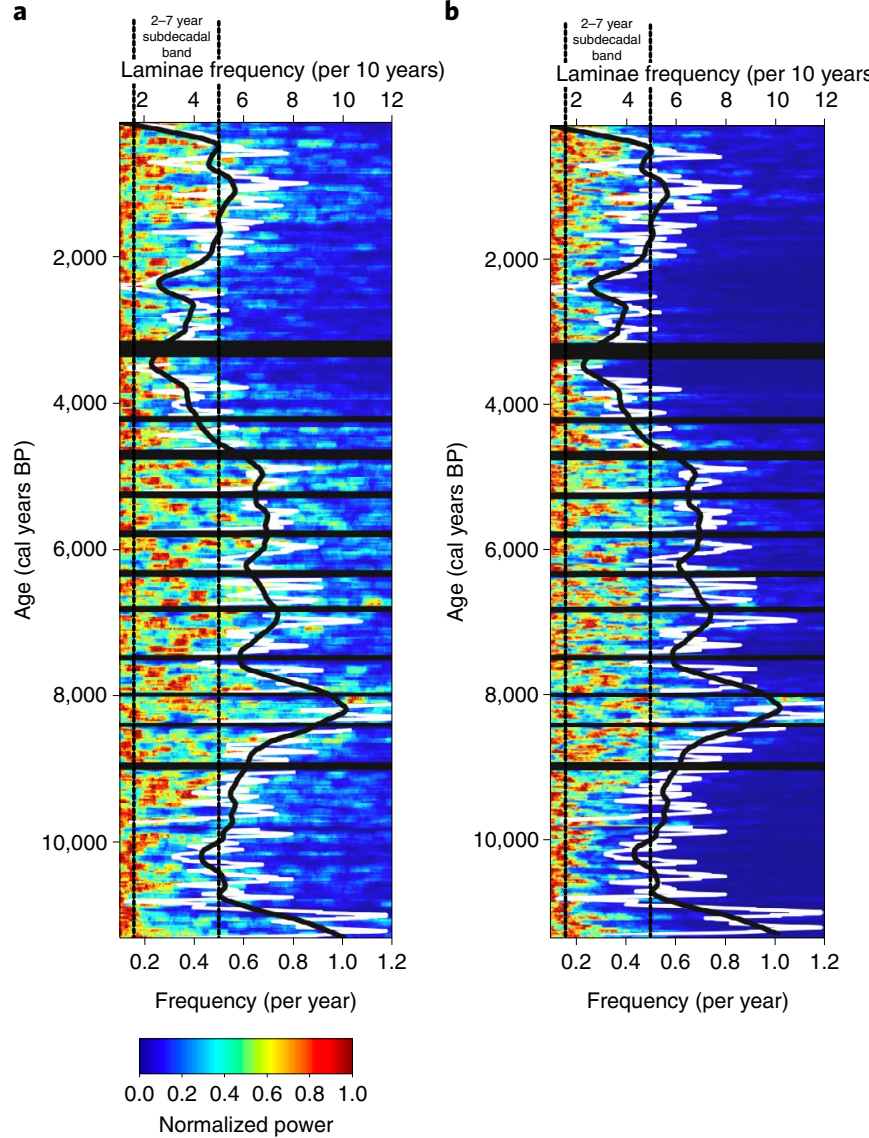

Fig. 4 | EHA of greyscale data and XRF Si/Ti productivity proxies. a, Greyscale data. b, XRF Si/Ti. Both plots are overlaid with curves of laminae frequency per 10 years in white and black (same as in Fig. 3d). Normalized power is similar across both proxies, showing a distinct shift to fewer bloom events and reduced productivity at $4.5 \mathrm{ka}$. Manual laminae counts binned at 10-year intervals are consistent with the EHA. The white curve is the 10-year binned record smoothed in a five-point moving mean, while the black curve is a rlowess smoothing, using a 5\% span of the unsmoothed 10-year binned record. The black boxes indicate intervals with no core recovery. The 2-7 year subdecadal climate mode band is indicated by vertical black dotted lines (that is, five laminae per 10 years is a 2-year frequency).

Ice Sheet retreat ${ }^{36,37}$. Deglacial reconstructions suggest a calving bay re-entrant pattern, whereby ice retreated first in the bathymetric troughs and later from the adjacent bathymetric highs ${ }^{36,37}$. This is supported by the decline in NGR and mean grain size, and gradual increased sorting of the detrital fraction upcore, representing a declining influence of glaciomarine sediment (Extended Data Figs. 5b and 7). The low MAR during this period may indicate less lateral advection of sediments as bathymetric highs were still ice-covered, restricting sediment transport from the east.

In contrast, the sharp MAR increase at $8.2 \mathrm{ka}$ likely indicates enhanced advection of material, initiated as the local bathymetric highs fully deglaciated (Fig. 3c). A high proportion of Chaetoceros (Hyalochaete) resting spores in diatom assemblages from MD032601 indicates a more stratified and stabilized water column than in later parts of the Holocene, supporting the interpretation of enhanced glacial meltwater at this time ${ }^{26,29}$. Stratified and nutrient-rich glacial meltwater ${ }^{38}$ likely created conditions favourable for bloom events.

The likely dominance of a local signal on sedimentation during the deglaciation suggests that regional processes (that is, meltwater stratification in an enclosed calving bay embayment) drove sea-ice seasonality/break-out and bloom events, not low-latitude teleconnections. A lack of fast ice, inferred from the $\mathrm{IPSO}_{25}$ proxy, allowed regular bloom events to occur in most seasons, and any subdecadal climate mode influences appear to have subordinate control. In this context, evolutionary harmonic analysis (EHA) of the CT greyscale curve and XRF Si/Ti linescan data shows power throughout the 2-7 year frequency band. Laminae counts occasionally fall into this band as well, consistent with subdecadal climate mode influences (Fig. 4). Although the annual sea-ice cycle appears to regulate bloom events during this period, we propose that subdecadal climate modes were a background influence, potentially causing earlier or later break-out of seasonal sea ice.

\section{Annual coastal sea-ice break-out modulated blooms ( 8 to $4.5 \mathrm{ka})$}

By $\sim 8 \mathrm{ka}$, regional interpretations suggest that glacial retreat was largely complete ${ }^{29,36}$, and U1357B grain size values, MARs and physical properties (for example, NGR and CT density values) stabilize, albeit with millennial-scale variations (Fig. 3 and Extended Data Fig. 5). Bloom events occur every $\sim 1-2$ years, and rarely fall into the 2-7 year subdecadal climate mode band (Fig. 4).

Sea-ice reconstructions from F. curta in MD03-2601 (ref. ${ }^{26}$ ) suggest reduced seasonal sea-ice duration, and $\mathrm{IPSO}_{25}$ data from U1357B indicate reduced fast ice cover compared with later intervals (Fig. 3f,g). Sand percent and MAR curves indicate stronger currents and high terrigenous sediment advection, implying enhanced wind stress due to reduced ice cover (Fig. 3c,e). A reduced duration of coastal ice in this region would increase the frequency of seasonal stratification from sea-ice meltwater and open water conditions. These conditions are currently observed to trigger diatom blooms in the Mertz Polynya ${ }^{39}$. Thus, during the relative warmth of the mid-Holocene ${ }^{29}$, we propose that the primary control on bloom events was the break-up and melting of seasonal sea ice. This is consistent with the observed shift towards annual to biennial laminae frequencies.

Although some studies suggest lower ENSO-related variability from Eastern Pacific equatorial records before $4.5 \mathrm{ka}$ (refs. ${ }^{30,31}$ ), a shift to lower variability does not explain more frequent sea-ice break-out and bloom events (Fig. 4). As with the preceding interval, spectral power in the 2-7 year band remains evident (Fig. 4), and a subordinate influence could account for break-out events' not occurring yearly. However, the annual cycle appears to be the dominant driver of coastal sea-ice break-out events throughout this interval.

\section{Increased coastal sea ice reduced productivity at $\mathbf{4 . 5} \mathrm{ka}$}

Around $4.5 \mathrm{ka}$, a shift occurred in all records (Fig. 3 and Extended Data Fig. 6), explained as a longer period of sea-ice cover in most years. This is reconstructed by diatom assemblages and $\mathrm{IPSO}_{25}$ proxies, and the decline in MARs and sand percent. Bloom events became less frequent and occurred approximately every 2-7 years. EHA analysis of the greyscale curve and $\mathrm{Si} / \mathrm{Ti} \mathrm{XRF}$ variance indicates a similar shift to the 2-7 year band (Figs. 3 and 4). Between 1.8 and $0.8 \mathrm{ka}$, there is an exception to this pattern. The $\mathrm{IPSO}_{25}$ data show a drop in fast ice, sand percent increases and laminae frequency increases to near-annual to biennial events (5-8 laminae events per 10 years; Fig. 4). Albeit a qualitative measure of fast ice ${ }^{28}$, we note a consistent pattern where IPSO $_{25}$ values are consistently low (for example $<0.2 \mu \mathrm{g} \mathrm{g}^{-1}$ ) and bloom events fall into the 1-2 year band (for example, 1.8 to $0.8 \mathrm{ka}$ ). When fast ice increases, bloom events fall into the 2-7 year band.

A reduction in primary productivity and, therefore, bloom events is expected with an overall increase in seasonal duration of sea-ice cover, due to reduced light availability and shorter growing season ${ }^{26}$. Extensive multi-year fast ice along George $\mathrm{V} \mathrm{Land}{ }^{23}$, 
to the east of U1357, significantly influences this region today. A regional increase in multi-year ice would reduce the occurrence of bloom events. Larger-scale seasonal sea-ice break-up would occur less frequently, thereby reducing the frequency of stratification events adjacent to the Mertz and Dumont d'Urville polynyas. The mechanism for increased sea-ice duration at $4.5 \mathrm{ka}$ is not a focus of this paper. It is noted around much of the Antarctic margin, being previously interpreted as a consequence of reduced local insolation forcing and enhanced ocean-ice shelf interactions ${ }^{21}$. Decreases in sand percent and MAR indicate an associated drop in current speed (Fig. 3c,e and Extended Data Fig. 3). This is likely due to expanded sea-ice coverage, which reduced wind stress on the ocean surface and the vigour of the coastal current. A slowdown in sedimentation rate is also observed at MD03-2601, indicating a regional slowdown in wind-driven current and sediment advection (Extended Data Fig. 1). These lines of evidence indicate that the shift in productivity and the reduced laminae frequency were due to increased presence and duration of coastal sea ice.

\section{Sea ice sets system sensitivity to subdecadal climate modes}

Although synoptic and katabatic winds are essential for opening and maintaining the Mertz Polynya, fast ice distributions are also important. Increased fast ice extent to the west and east restrict sea-ice export and 'back-fill' the polynya, thereby limiting its size ${ }^{40}$. Greater fast ice extent over Site U1357, which lies to the west of the Mertz Polynya (Fig. 1), would increase the probability of back-fill events, limiting bloom events. However, greater fast ice extent could also increase stratification during favourable conditions for sea-ice break-out.

Our Adélie Land record shows that the frequency of mass biogenic bloom events in coastal polynyas of Adélie Land, East Antarctica is strongly modulated by coastal sea ice. The 2-7 year variability in bloom events, consistent with subdecadal climate mode forcing, increased after $4.5 \mathrm{ka}$. This agrees with other Antarctic Holocene records which suggest increased impacts of subdecadal climate modes on westerly winds and surface temperatures in the late Holocene ${ }^{19,41}$. Changing seasonality and distribution of coastal sea ice, and shifts in zonal winds are modulated by subdecadal climate modes under modern conditions ${ }^{8-10,14}$. We propose that the increased extent of coastal ice at $4.5 \mathrm{ka}$ accentuated the impact of subdecadal climate modes on sea-ice break-out. This caused biogenic blooms to shift from annual/biennial events to subdecadal-scale modulation.

This is relevant to projections of Antarctic coastal change, as Adélie Land climate anomalies associated with climate modes differ among reanalysis studies ${ }^{9,42-44}$. Climate models also struggle to capture recent sea-ice trends, due to the complexities of ocean and atmospheric feedbacks in the Antarctic ${ }^{45}$. Thus, critical processes appear to be underrepresented in models which project the future response of Antarctic coastal systems to increased tropical and southern mid-latitude variability.

Our data highlight the importance of sea-ice dynamics in regulating the sensitivity of biological productivity to subdecadal-scale climate modes (for example, ENSO, SAM and IOD) along the Adélie Land margin. If future warming trends result in reduction or loss of coastal sea ice, as occurred during the mid-Holocene at Adélie Land, our work suggests that more frequent bloom events will result, independent of background shifts in subdecadal-scale climate modes. This has implications for future food webs in the Antarctic, and carbon cycling processes within this globally important region of $\mathrm{AABW}$ formation.

\section{Online content}

Any methods, additional references, Nature Research reporting summaries, source data, extended data, supplementary information, acknowledgements, peer review information; details of author contributions and competing interests; and statements of data and code availability are available at https://doi.org/10.1038/ s41561-021-00816-y.

Received: 14 October 2019; Accepted: 16 July 2021; Published online: 9 September 2021

\section{References}

1. Arrigo, K. R., van Dijken, G. \& Long, M. Coastal Southern Ocean: a strong anthropogenic $\mathrm{CO}_{2}$ sink. Geophys. Res. Lett. 35, L21602 (2008).

2. Rintoul, S. R. On the origin and influence of Adélie Land bottom water. Antarct. Res. Ser. 75, 151-171 (1998).

3. Moore, J. K. \& Abbott, M. R. Phytoplankton chlorophyll distributions and primary production in the Southern Ocean. J. Geophys. Res. Ocean. 105, 28709-28722 (2000).

4. Arrigo, K. R. \& van Dijken, G. L. Phytoplankton dynamics within 37 Antarctic coastal polynya systems. J. Geophys. Res. C. 108, 1-18 (2003).

5. Comiso, J. C., McClain, C. R., Sullivan, C. W., Ryan, J. P. \& Leonard, C. L. Coastal zone color scanner pigment concentrations in the Southern Ocean and relationships to geophysical surface features. J. Geophys. Res. 98, 2419-2451 (1993)

6. Smith, W. O. \& Nelson, D. M. Importance of ice edge phytoplankton production in the Southern Ocean. Bioscience 36, 251-257 (1986).

7. Rigual-Hernández, A. S., Trull, T. W., Bray, S. G., Closset, I. \& Armand, L. K. Seasonal dynamics in diatom and particulate export fluxes to the deep sea in the Australian sector of the southern Antarctic Zone. J. Mar. Syst. 142, 62-74 (2015).

8. Yuan, X. ENSO-related impacts on Antarctic sea ice: a synthesis of phenomenon and mechanisms. Antarct. Sci. 16, 415-425 (2004).

9. Nuncio, M. \& Yuan, X. The influence of the Indian Ocean dipole on Antarctic sea ice. J. Clim. 28, 2682-2690 (2015).

10. L'Heureux, M. L. \& Thompson, D. W. J. Observed relationships between the El Niño Southern Oscillation and the extratropical zonal-mean circulation. J. Clim. 19, 276-287 (2006).

11. Stammerjohn, S. E., Martinson, D. G., Smith, R. C., Yuan, X. \& Rind, D. Trends in Antarctic annual sea ice retreat and advance and their relation to El Niño-Southern Oscillation and Southern Annular Mode variability. J. Geophys. Res. 113, C03S90 (2008).

12. Fogt, R. L., Bromwich, D. H. \& Hines, K. M. Understanding the SAM influence on the South Pacific ENSO teleconnection. Clim. Dyn. 36, 1555-1576 (2011).

13. Saba, G. K. et al. Winter and spring controls on the summer food web of the coastal West Antarctic Peninsula. Nat. Commun. 5, 1-8 (2014).

14. Arrigo, K. R. \& Van Dijken, G. L. Annual changes in sea-ice, chlorophyll a, and primary production in the Ross Sea, Antarctica. Deep. Res. Part II Top. Stud. Oceanogr. 51, 117-138 (2004).

15. Venables, H. J., Clarke, A. \& Meredith, M. P. Wintertime controls on summer stratification and productivity at the western Antarctic Peninsula. Limnol. Oceanogr. 58, 1035-1047 (2013).

16. Mayewski, P. A. et al. State of the antarctic and southern ocean climate system. Rev. Geophys. 47, 1-38 (2009).

17. Escutia, C., Brinkhuis, H., Klaus, A. \& Expedition 318 Scientists. Site U1357. In Proc. IODP Vol. 318 (IODP, 2011).

18. Shevenell, A. E., Ingalls, A. E., Domack, E. W. \& Kelly, C. Holocene Southern Ocean surface temperature variability west of the Antarctic Peninsula. Nature 470, 250-254 (2011).

19. Pike, J., Swann, G. E. A., Leng, M. J. \& Snelling, A. M. Glacial discharge along the west Antarctic Peninsula during the Holocene. Nat. Geosci. 6, 199-202 (2013)

20. Whitworth, T. et al. in Ocean, Ice, and Atmosphere: Interactions at the Antarctic Continental Margin (eds. Jacobs, S. S. \& Weiss, R. F.) 75, 1-27 (American Geophysical Union, 1998).

21. Ashley, K. E. et al. Mid-Holocene Antarctic sea-ice increase driven by marine ice sheet retreat. Clim. Past 17, 1-19 (2021).

22. Dunbar, R. B., Anderson, J. B., Domack, E. W. \& Jacobs, S. S. in Oceanology of the Antarctic Continental Shelf (ed. Jacobs, S. S.) 309-312 (American Geophysical Union, 1985).

23. Massom, R. A. et al. Change and variability in East Antarctic sea ice seasonality, 1979/80-2009/10. PLoS ONE 8, e64756 (2013).

24. Denis, D. et al. Seasonal and subseasonal climate changes recorded in laminated diatom ooze sediments, Adélie Land, East Antarctica. Holocene 16 1137-1147 (2006).

25. Maddison, E. J., Pike, J. \& Dunbar, R. B. Seasonally laminated diatom-rich sediments from Dumont d'Urville Trough, East Antarctic Margin: Late-Holocene Neoglacial sea-ice conditions. Holocene 22, 857-875 (2012).

26. Denis, D. et al. Holocene productivity changes off Adélie Land (East Antarctica). Paleoceanography 24, PA3207 (2009). 
27. Crosta, X., Debret, M., Denis, D., Courty, M. A. \& Ther, O. Holocene long-and short-term climate changes off Adélie Land, East Antarctica. Geochem. Geophys. Geosyst. 8, 1-15 (2007).

28. Belt, S. T. et al. Source identification and distribution reveals the potential of the geochemical Antarctic sea ice proxy $\mathrm{IPSO}_{25}$. Nat. Commun. 7, 12655 (2016).

29. Crosta, X., Denis, D. \& Ther, O. Sea ice seasonality during the Holocene, Adélie Land, East Antarctica. Mar. Micropaleontol. 66, 222-232 (2008).

30. Moy, C. M., Seltzer, G. O., Rodbell, D. T. \& Anderson, D. M. Variability of El Niño/Southern Oscillation activity at millennial timescales during the Holocene epoch. Nature 420, 162-165 (2002).

31. Carré, M. et al. Holocene history of ENSO variance and asymmetry in the eastern tropical Pacific. Science 345, 1045-1047 (2014).

32. Cobb, K. M. et al. Highly variable El Niño-Southern Oscillation throughout the Holocene. Science 339, 67-70 (2013).

33. Karamperidou, C., Di Nezio, P. N., Timmermann, A., Jin, F.-F. \& Cobb, K. M. The response of ENSO flavors to mid-Holocene climate: implications for proxy interpretation. Paleoceanography 30, 527-547 (2017).

34. Abram, N. J. et al. Evolution of the Southern Annular Mode during the past millennium. Nat. Clim. Change 4, 564-569 (2014).

35. Abram, N. J. et al. Palaeoclimate perspectives on the Indian Ocean Dipole. Quat. Sci. Rev. 237, 106302 (2020).

36. Mackintosh, A. N. et al. Retreat history of the East Antarctic Ice Sheet since the Last Glacial Maximum. Quat. Sci. Rev. 100, 10-30 (2014).

37. Leventer, A. et al. Marine sediment record from the East Antarctic margin reveals dynamics of ice sheet recession. GSA Today 16, 4-10 (2006).

38. Gerringa, L. J. A. et al. Iron from melting glaciers fuels the phytoplankton blooms in Amundsen Sea (Southern Ocean): iron biogeochemistry. Deep Sea Res. II 71-76, 16-31 (2012).

39. Moreau, S. et al. Sea ice meltwater and circumpolar deep water drive contrasting productivity in three Antarctic polynyas. J. Geophys. Res. Ocean. 124, 2943-2968 (2019).
40. Massom, R. A. et al. Effects of regional fast-ice and iceberg distributions on the behaviour of the Mertz Glacier polynya, East Antarctica. Ann. Glaciol. 33, 391-398 (2001)

41. Etourneau, J. et al. Holocene climate variations in the western Antarctic Peninsula: evidence for sea ice extent predominantly controlled by changes in insolation and ENSO variability. Clim. Past 9, 1431-1446 (2013).

42. Schneider, D. P. et al. Observed Antarctic interannual climate variability and tropical linkages. J. Clim. 25, 4048-4066 (2012).

43. Ciasto, L. M. et al. Teleconnections between tropical Pacific SST anomalies and extratropical Southern Hemisphere climate. J. Clim. 28, 56-65 (2015).

44. Marshall, G. J. \& Thompson, D. W. J. The signatures of large-scale patterns of atmospheric variability in Antarctic surface temperatures. J. Geophys. Res. Atmos. 121, 3276-3289 (2016)

45. IPCC Special Report on the Ocean and Cryosphere in a Changing Climate (eds Weyer, N. M. et al.) (IPCC, 2019).

46. Mouginot, J., Scheuchl, B. \& Rignot, E. MEaSUREs Antarctic boundaries for IPY 2007-2009 from Satellite Radar, Version 2. [68 $\left.{ }^{\circ}, 65^{\circ} \mathrm{S} ; 148^{\circ} \mathrm{E}, 138^{\circ} \mathrm{E}\right]$ (NASA National Snow and Ice Data Center, 2017).

47. Fretwell, P. et al. Bedmap2: improved ice bed, surface and thickness datasets for Antarctica. Cryosphere 7, 375-393 (2013).

48. Beaman, R. J., O’Brien, P. E., Post, A. L. \& De Santis, L. A new high-resolution bathymetry model for the Terre Adélie and George V continental margin, East Antarctica. Antarct. Sci. 23, 95-103 (2011).

49. NASA Ocean Biology Processing Group. MODIS-Aqua Level 2 Ocean Color Data Version R2018.0 NASA Ocean Biology DAAC (2017); https://doi. org/10.5067/AQUA/MODIS/L2/OC/2018

50. Hu, C., Lee, Z. \& Franz, B. Chlorophyll a algorithms for oligotrophic oceans: a novel approach based on three-band reflectance difference. J. Geophys. Res. 117, C01011 (2012).

Publisher's note Springer Nature remains neutral with regard to jurisdictional claims in published maps and institutional affiliations.

(c) The Author(s), under exclusive licence to Springer Nature Limited 2021 


\section{Methods}

Age model. The age model was developed from $87{ }^{14} \mathrm{C}$ dates from acid-insoluble bulk sedimentary organic carbon to constrain the ages of the sediment between $\sim 11.4 \mathrm{ka} \mathrm{BP}$ and modern day ${ }^{21}$ (Extended Data Fig. 1). The age model only resolves ages to $11.4 \mathrm{ka}$ as ages older than this are anomalously old and assumed to incorporate reworked carbon of pre-Last Glacial Maximum age. This was also indicated by a larger terrestrial contribution observed at the lowest section of the core according to XRF data ${ }^{51}$. Ages younger than $11.4 \mathrm{ka}$ are less likely to be affected by reworked carbon at the Adélie Drift site, as lack of IRD suggests that direct glacial influences were negligible. The consistent stratigraphic order of the 87 radiocarbon ages and sedimentation rates through the Holocene supports this interpretation. Very few Antarctic marine sediment core records presently have age models of this resolution and with this level of stratigraphic integrity. A reservoir correction age of $1,200 \pm 100$ was applied to the depth-to-age conversion calculated by BACON, which uses a Bayesian iteration scheme that invokes memory from dates above any given horizon and produces a weighted mean and median age-depth curve ${ }^{52}$. This correction is consistent with the uncalibrated age of the uppermost sample of 1,310 years.

Since $\mathrm{C}_{16}$ fatty acids decompose rapidly in the water column and sediment ${ }^{53,54}$ compound-specific (CS) ages in Antarctic sediments that contain relict carbon from glacial reworked sediments often show younger ages than bulk ages ${ }^{5,56}$. Yamane et al. (2014) reported an age model based on $\mathrm{CS}^{14} \mathrm{C}$ ages using $\mathrm{C}_{16}$ fatty acids from core U1357A, and ages were reported with one-sigma uncertainty. In this study, the background level of the study was rigorously re-examined using the latest background evaluation method for small-scale ${ }^{14} \mathrm{C}$ analysis developed at the Atmosphere and Ocean Research Institute, University of Toky ${ }^{57}$. The modern carbon contamination (MCC) was evaluated from ${ }^{14} \mathrm{C}$ value of IAEA-C4 (wood: $\Delta^{14} \mathrm{C}=-998.0$ to $-995.6 \%$ ) which was processed and measured by accelerator mass spectrometry in the same batch as other unknown samples (Supplementary Fig. 1a). The background correction was carried out differently depending on sample size using the relationship between sample size and background (Supplementary Fig. 1b). To externally evaluate the reliability of the MCC, we estimated the core-top CS ${ }^{14} \mathrm{C}$ value using the mean sedimentation rate of lithostratigraphic unit I (0-170.25 m below seafloor). Based on the revised CS ${ }^{14} \mathrm{C}$ ages, it is estimated that the $\Delta^{14} \mathrm{C}$ value of core-top sediment is about $-147 \%$. This $\Delta^{14} \mathrm{C}$ value is in agreement with the pre-bomb dissolved inorganic carbon (DIC) $\Delta^{14} \mathrm{C}$ value of the Southern Ocean $\left(-149.8+10.4 \%\right.$; ref. $\left.{ }^{58}\right)$, hence validating the $C S{ }^{14} \mathrm{C}$. The values are co-plotted with bulk ages with two-sigma uncertainties and show that $\mathrm{CS}$ and bulk organic ${ }^{14} \mathrm{C}$ ages are consistent (Extended Data Fig. 1). This is the case for earlier values (that is, ref. ${ }^{51}$ ) if we plotted values with two-sigma uncertainties, thus all ages are consistent within statistical uncertainties. Consequently, these revised compound-specific radiocarbon assessments support our inference that contamination of reworked carbon in these rapidly deposited biogenic-rich samples is minimal (Supplementary Table 1). Below, we independently assess the reliability of the bulk organic carbon age model by comparison with age models from the nearby core MD03-2601 (Extended Data Fig. 1).

The BACON methodology was applied to the ${ }^{14} \mathrm{C}$ dates from MD03-2601 (refs. ${ }^{27,29}$ ) to recalibrate the MD03-2601 age model ${ }^{21}$. The model shown in this paper is different from the one used previously $y^{59}$, which used an inferred meteorite impact at $\sim 15 \mathrm{~m}$ to determine an age of $4 \mathrm{ka}$ at that depth. The old age model also removed two ${ }^{14} \mathrm{C}$ dates at 4.4 and 5.6 ka years due to the assumption that these ages were anomalously old relative to the meteorite impact. However, the meteorite age-depth correlation cannot provide absolute age control, and the new age model presented herein indicates that the impact occurred at around $5.4 \mathrm{ka}$. Comparison between the U1357B and new MD03-2601 age model show strong covariance in sedimentation rates and suggest a regional sedimentation advection process (Extended Data Fig. 1).

Depth scales. Core recovery from each $9.5 \mathrm{~m}$ piston core run often exceeded $100 \%$ due to expansion as the core decompressed during recovery. Data derived from these initial core lengths are termed the csf-a depth scale. The standard IODP procedure to correct for expansion is to apply a linear compression algorithm to scale recovery back to $100 \%$ and create a new scale (csf-b), as it is assumed that expansion is uniform in the core. However, in U1357, expansion due to biogenic gas was particularly high and resulted in discrete sections of core being pushed apart, creating voids in the depth scale that did not represent real gaps in the stratigraphy. To account for this, the voids are numerically removed, and the depth scale adjusted, before linear compression is applied (if recovery still exceeds $100 \%$ ). In this paper, we term this the csf-d scale (noting that this is not an official IODP depth scale term). Although cap expansion gaps (voids) are removed within individual core runs, the csf-d scale still contains sections with no core recovery at the base of some runs where there was less than $100 \%$ after voids within the cores were numerically removed. The sections with no core recovery were as follows: $48.82-50.0 \mathrm{~m}, 58-59.5 \mathrm{~m}, 66.19-69.0 \mathrm{~m}, 76.81-78.5 \mathrm{~m}$, 86.5-88.0 m, 95.66-97.5 m, 105.16-107.0 m, 115.72-116.5 m, 124.38-126.0 m, $134.41-135.5 \mathrm{~m}, 144.23-145 \mathrm{~m}, 153.85-154.5 \mathrm{~m}$ and $163.94-164.0 \mathrm{~m}$. Slight differences in these depths could have occurred in core storage before CT and XRF scans.
Composite core. Three holes (U1357A, B and C) were drilled in the Adélie Basin as part of IODP expedition $318\left(\right.$ ref. $\left.{ }^{17}\right)$. Drilling multiple holes is standard IODP procedure for sites with palaeoceanographic focus to address core breaks and other intervals of incomplete recovery; a complete and continuous stratigraphy can usually be constructed by splicing sections from individual holes into a stratigraphic composite section. This is usually achieved in IODP cores by using physical core properties to guide placement of the least disturbed, highest recovery intervals in the spliced sections. However, cores from Site U1357 are problematic in this context as extremely high biogenic and gaseous content precluded many physical property measurements, such as magnetic susceptibility, from being registered beyond typical noise levels. This made construction of a composite core at subcentennial-scale precision extremely difficult. Given the difficulties in creating a spliced record, hole U1357B was selected as the best core for this analysis because it had less gas-related disturbances than hole $\mathrm{A}$, and a more complete record than hole $\mathrm{C}$, which produced a shorter core. Additionally, it also has a higher-resolution age model.

Linear sedimentation rates. The linear sedimentation rates were calculated for every centimetre using the age-depth model above. These were then binned every $10 \mathrm{~cm}$.

MARs. Terrigenous and biogenic MARs were calculated using the formula below:

$$
\text { MAR }=\% X \times(\text { LSR } \times \text { BD })
$$

MAR $=$ mass accumulation rate $\left(\mathrm{g} \mathrm{cm}^{-2}\right.$ per year $)$

$\mathrm{LSR}=$ linear sedimentation rate $(\mathrm{cm}$ per year)

$X=$ percent abundance of the component of interest (that is, terrigenous or biogenic)

$\mathrm{BD}=$ bulk density $\left(\mathrm{g} \mathrm{cm}^{-3}\right)$

Shipboard bulk density measurements were not collected on the U1357B core, which was preserved as whole-round sections until post-expedition sampling several months after collection. Moisture and density (MAD) bulk densities from the U1357A core (collected at the same site location) were used instead, with a linear fit taken though these data to derive a downhole estimate of bulk density ${ }^{17}$. The associated depths of these discrete samples were converted to age using the U1357A age-depth model. This model uses 36 bulk organic carbon dates and demonstrates the age versus depth relationship using the same Bayesian approach used in the U1357B age model. A linear fit between the age and density measurements of U1357A was interpolated to the U1357B age scale to determine the densities for U1357B. Biogenic silica and terrigenous percentage were determined using alkaline extraction spectrophotometric methods ${ }^{60}$.

Grain size analysis. Grain size analysis was performed on 341 samples. Samples were treated twice with $1 \mathrm{M}$ sodium hydroxide $(\mathrm{NaOH})$ solution in an $80^{\circ} \mathrm{C}$ water bath for $24 \mathrm{~h}$ to remove biogenic opal, then treated with hydrogen peroxide $\left(\mathrm{H}_{2} \mathrm{O}_{2}\right)$ to remove organic material. As terrigenous material formed a minor component of the bulk sediment, post-treatment sample mass varied from $\sim 0.035$ to $0.8 \mathrm{~g}$. Samples were measured on a Beckman Coulter LS 13320 laser diffraction particle size analyser. Eighty-four sub-samples were taken after chemical treatment with $\mathrm{NaOH}$ and $\mathrm{H}_{2} \mathrm{O}_{2}$ to assess reproducibility. Twelve samples were split into two subsamples, and chemical treatment was performed on each subsample to test for biases relating to subsampling and chemical dissolution. Correlations calculated using least-squares regression between the original and repeat measurements were $r^{2}=0.74$ for the post chemical treatment replicates and $r^{2}=0.75$ for the pre-chemical treatment replicates.

Computed tomography scans. X-ray computed tomography (CT) scanners quantify the amount of X-ray energy absorbed (attenuated) by a particular object and display the resulting attenuation coefficients as a greyscale image ${ }^{61}$. Pixel values within these images are expressed as greyscale values or Hounsfield units (also known as CT number) which are calculated by comparing the sample attenuation coefficient with that of water ${ }^{15}$

$\mathrm{X}$-ray attenuation is a function of the density, porosity, chemical composition and grain size of the sample ${ }^{62}$. Brighter areas in the image represent higher attenuation, while darker areas represent lower attenuation. CT scans were completed on core U1357B using a Toshiba Aquilion TXL CT scanner at the Department of Petroleum Engineering, Texas A\&M University. Axial scans were completed at $135 \mathrm{kV}_{\mathrm{p}}$ and $200 \mathrm{~mA}$, and coronal slices were created in open-source HOROS software ${ }^{63}$. The resolution averages 1.3 pixels per millimetre, and each core was exported as its own Digital Imaging and Communications in Medicine image stack which contained 512 images. From there, the best image (accounting for cracks and other spaces in the core) from each stack was selected and exported to another $\mathrm{CT}$ processing software $\left(\mathrm{FIJI}^{64}\right)$ for greyscale analysis and laminae counting.

$\mathrm{HBI} /$ isoprenoid/IPSO${ }_{25}$ data. $\mathrm{IPSO}_{25}$ is another name for the highly branched isoprenoid (HBI) lipid biomarker (diene II). $\mathrm{C}_{25}$ - $\mathrm{HBI}$ alkenes, in particular the di-unsaturated $\mathrm{C}_{25}$-HBI with a double bond, also referred to as diene, were extracted at Laboratoire d'Océanographie et du Climat: Experimentations et 
Approches Numériques, using a mixture of $9 \mathrm{~mL} \mathrm{CH}_{2} \mathrm{Cl}_{2} / \mathrm{MeOH}(2: 1, \mathrm{v}: \mathrm{v})$ to which internal standards (7-hexyl nonadecane, 9-octyl heptadecene and androstanol) were added; several sonication and centrifugation steps were applied in order to properly extract the selected compounds ${ }^{41}$. After drying with $\mathrm{N}_{2}$ at $35^{\circ} \mathrm{C}$, the total lipid extract was fractionated over a silica column into an apolar and polar fraction using $3 \mathrm{~mL}$ hexane and $6 \mathrm{~mL} \mathrm{CH}_{2} \mathrm{Cl}_{2} / \mathrm{MeOH}(1: 1, \mathrm{v}: \mathrm{v})$, respectively. HBIs were obtained from the apolar fraction by fractionation over a silica column using hexane as eluent following the procedures reported in refs. ${ }^{65,66}$. After removing the solvent with $\mathrm{N}_{2}$ at $35^{\circ} \mathrm{C}$, elemental sulphur was removed using the tetrabutylammonium sulphite method ${ }^{67,68}$. The obtained hydrocarbon fraction was analysed using an Agilent 7890A gas chromatograph (GC) fitted with $30 \mathrm{~m}$ fused silica Agilent J\&C GC column ( $0.25 \mathrm{~mm}$ i.d., $0.25 \mu \mathrm{m}$ film thickness), coupled to an Agilent 5975 C series mass selective detector. Spectra were collected using Agilent MS-Chemstation software. Individual HBIs were identified on the basis of comparison between their GC retention times and mass spectra with those of previously authenticated HBIs (for example, from ref. ${ }^{69}$ ) using Mass Hunter software.

Image analysis. Greyscale curve. Any pixel value less than zero was converted to non-values (NaNs) by thresholding the images in FIJI ${ }^{64}$. This eliminated noise from pervasive sub-millimetre to millimetre-scale cracks resulting from expansion due to biogenic gas in the cores (Extended Data Fig. 4).

A single greyscale curve was created by taking a line profile of the greyscale image for each core. The line profile was four pixels wide, with the pixel value of each row being the average of these four pixels. The profile was chosen to minimize core disruptions. Many CT studies choose to average all rows across the whole width of the image, but this was not possible due to the middle of this core having previously been sampled using U-Channel methods, and due to dipping of the laminae along the core liner. These image curves were then corrected for any depth offset introduced by the core liner and CT machine, and concatenated into a final dataset.

Laminae counts. The top and bottom of bright laminae were picked manually throughout the entire core.

Some laminae had sharp divisions between bright and dark pixels, while others had a gradual transition. In addition, some bright laminae were interspersed among a slightly lighter background, making it difficult to distinguish between multiple laminae and single events. We counted such intervals as a single lamina, and suggest that these could represent seasons when there were multiple blooms or prolonged bloom events. Visual picking of the laminae can be subjective, but was preferred over automated methods due to noise produced by gas expansion cracks, which varied from core to core. To assess this subjective aspect, laminae picks were visually overlaid on the greyscale curve to evaluate consistency throughout the length of the core (Extended Data Fig. 4). Some laminae were disrupted by cracks. We manually removed the laminae disrupted by several centimetres or more, but these accounted for less than $0.1 \%$ of laminae. Laminae were binned into 10 -year intervals (Figs. 3 and 4). For bins that contained a missing interval, that is, the base of a $9.5 \mathrm{~m}$ core run where recovery was $<100 \%$, the binned laminae amounts were scaled to represent the actual number of years per bin. For the scaled 10-year bins, seven data points were removed because the bins contained fewer than 2 years of data. Comparison of the manually picked laminae with evolutionary spectra of the raw greyscale curve and $\mathrm{Si} / \mathrm{Ti}$ values from XRF linescan data was conducted to independently verify the frequencies identified (Fig. 4).

Evolutionary spectral analysis. Before analysis, the greyscale data were interpolated to 0.1 years (from an average spacing of 0.041 years) and the XRF data were interpolated to 0.4 years (from an average time step of 0.44 years), using piecewise-linear interpolation. EHA using the Thomson multi-taper method to determine power spectra was performed in the R package 'Astrochron ${ }^{\text {'70 }}$ using both the XRF and CT greyscale data. Outliers were removed from the series using the 'Trim' function in Astrochron, which uses a box plot algorithm with a coefficient of 1.5 to identify values greater than or less than 1.5 times the interquartile range from quartile 3 and quartile 1, respectively. For EHA on the CT greyscale data, a multi-taper method time-bandwidth product of 4 , window width of 100 years and step size of 20 years were used. For the lower-resolution XRF data, a multi-taper method time-bandwidth product of 3 , window width of 70 years and step size of 10 year were used. Resulting spectra were seen to be relatively insensitive to window width and step size, and time series analysis on other XRF productivity proxies $(\mathrm{Ba} / \mathrm{Ti}, \mathrm{Si} / \mathrm{Al})$ yielded similar results. In all datasets analysed, power was normalized so that the maximum power in each window is unity.

The manual laminae counts, binned into 10-year intervals, were then overlaid on the EHA results and show consistent centennial-scale shifts in the power of the 2-7 year frequency bands. This indicates that binned laminae frequencies are representative of the EHA results and are able to capture higher-frequency variations in bloom events.

XRF. XRF data were measured using an AVAATECH XRF core scanner at the Joint Oceanographic Institutions for Deep Earth Sampling (JOIDES) Resolution Science Operator XRF facility, located at the Gulf Coast Repository at Texas A\&M
University Research Park. Measurements were undertaken at $0.5 \mathrm{~cm}$ resolution (where possible) with a $5 \mathrm{~mm}$ slit size using generator settings of $10 \mathrm{kV}$ and current of $0.8 \mathrm{~mA}$. The sampling time was set at $45 \mathrm{~s}$, and scanning took place directly at the split core surface of the archive half. The split core surface was covered with a 4-micron thin SPEXCerti Prep Ultralenel foil to avoid contamination of the XRF measurement unit and desiccation of the sediment.

Biogenic silica concentrations in sediments (\%BSi) are commonly used as an indicator of past diatom and radiolarian productivity in high-latitude marine sediments (see, for example, refs. ${ }^{71,72}$ ). Silicon ( $\mathrm{Si}$ ) is the main component of biogenic opal, and Si-based ratios are commonly used as \%BSi proxies ${ }^{73}$. Estimating $\% \mathrm{BSi}$ from Si content or Si-based ratios obtained by XRF scanner requires site-specific calibration, but comparison with the $\mathrm{Si} / \mathrm{Ti}$ ratio shows distribution almost parallel with \%BSi records as a function of depth (see, for example, ref.

$\left.{ }^{73}\right)$. Nevertheless, use of $\mathrm{Si}$ as a productivity proxy should be applied with caution, because $\mathrm{Si}$ can also be controlled by siliciclastic material during low-productivity periods, even in polar regions ${ }^{74}$, and light elements, such as $\mathrm{Si}$ or $\mathrm{Al}$, have low detectability by XRF scanner measurements when present in low concentrations ${ }^{75}$.

Site U1357B is a laminated diatom ooze. Diatom content estimated from smear slides has a mean of $91 \%$ (ref. ${ }^{17}$ ). \%BSi content in this study ranges from $30 \%$ to $63 \%$ with an average of $48 \% \mathrm{BSi}$ for the late Holocene. Si detection by the $\mathrm{XRF}$ scanner is not an issue, as the average Si peak area is $\sim 200,000$ counts. In any case, the high opal content masks Si input related to siliciclastic material. To correct dilution effect and obtain a first-order discrimination between biogenic and detrital $\mathrm{Si}$, we normalized $\mathrm{Si}$ to $\mathrm{Ti}$. This normalization assumes that $\mathrm{Ti}$ is a conservative element associated only with the terrigenous fraction and $\mathrm{Si} / \mathrm{Ti}$ ratio of the terrigenous matter remains almost constant over the period studied. We use the obtained $\mathrm{Si} / \mathrm{Ti}$ ratio as a semi-quantitative record of the siliceous productivity, in agreement with previous studies that use $\mathrm{Si} / \mathrm{Ti}$ or equivalent ratios as a productivity proxy in both marine $\mathrm{e}^{76,77}$ and lacustrine records $\mathrm{s}^{78,79}$.

Correlation analysis between laminae counts, biogenic MAR and sand percent. Laminae counts, biogenic MAR and sand percent were linearly interpolated to a common 100-year step. Regression statistics were calculated from 10,050 BP onwards, as the glaciated environment before this time is not representative of current relationships.

\section{Data availability}

The raw greyscale data, light laminae depths, light laminae sand percent, XRF silicon, XRF titanium and HBI diene data for IODP Site U1357B are available at https://doi.org/10.1594/PANGAEA.933380.

\section{References}

51. Yamane, M. et al. Compound-specific ${ }^{14} \mathrm{C}$ dating of IODP expedition 318 core U1357A obtained off the Wilkes Land coast, Antarctica. Radiocarbon 56, 1009-1017 (2014).

52. Blaauw, M. \& Christen, J. A. Flexible paleoclimate age-depth models using an autoregressive gamma process. Bayesian Anal. 6, 457-474 (2011).

53. Canuel, E. A. \& Martens, C. S. Reactivity of recently deposited organic matter: degradation of lipid compounds near the sediment-water interface. Geochim. Cosmochim. Acta 60, 1793-1806 (1996).

54. Ohkouchi, N., Kawamura, K. \& Taira, A. Fluctuations of terrestrial and marine biomarkers in the western tropical Pacific during the last 23,300 years. Paleoceanography 12, 623-630 (1997).

55. Yokoyama, Y. et al. Widespread collapse of the Ross Ice Shelf during the late Holocene. Proc. Natl Acad. Sci. USA 113, 2354-2359 (2016).

56. Prothro, L. O. et al. Timing and pathways of East Antarctic Ice Sheet retreat. Quat. Sci. Rev. 230, 106166 (2020).

57. Yamane, M. et al. Small- to ultra-small-scale radiocarbon measurements using newly installed single-stage AMS at the University of Tokyo. Nucl. Instrum. Methods Phys. Res. B 455, 238-243 (2019).

58. Berkman, P. A. \& Forman, S. L. Pre-bomb radiocarbon and the reservoir correction for calcareous marine species in the Southern Ocean. Geophys. Res. Lett. 23, 363-366 (1996).

59. Denis, D. et al. Holocene glacier and deep water dynamics, Adélie Land region, East Antarctica. Quat. Sci. Rev. 28, 1291-1303 (2009).

60. Mortlock, R. A. \& Froelich, P. N. A simple method for the rapid determination of biogenic opal in pelagic marine sediments. Deep Sea Res. A 36, 1415-1426 (1989).

61. St-Onge, G. \& Long, B. F. CAT-scan analysis of sedimentary sequences: an ultrahigh-resolution paleoclimatic tool. Eng. Geol. 103, 127-133 (2009).

62. Boespflug, X., Long, B. F. N. \& Occhietti, S. CAT-scan in marine stratigraphy: a quantitative approach. Mar. Geol. 122, 281-301 (1995)

63. Horos Project (Horos, 2017)

64. Schindelin, J. et al. Fiji: an open-source platform for biological-image analysis Nat. Methods 9, 676-682 (2012).

65. Belt, S. T. et al. A novel chemical fossil of palaeo sea ice: IP25. Org. Geochem. 38, 16-27 (2007). 
66. Massé, G. et al. Highly branched isoprenoids as proxies for variable sea ice conditions in the Southern Ocean. Antarct. Sci. 23, 487-498 (2011).

67. Jensen, S., Renberg, L. \& Reutergårdh, L. Residue analysis of sediment and sewage sludge for organochlorines in the presence of elemental sulfur. Anal. Chem. 49, 316-318 (1977)

68. Riis, V. \& Babel, W. Removal of sulfur interfering in the analysis of organochlorines by GC-ECD. Analyst 124, 1771-1773 (1999).

69. Johns, L. et al. Identification of a $\mathrm{C}_{25}$ highly branched isoprenoid (HBI) diene in Antarctic sediments, Antarctic sea-ice diatoms and cultured diatoms. Org. Geochem. 30, 1471-1475 (1999).

70. Meyers, S. Astrochron: An R Package for Astrochronology (CRAN, 2014).

71. Ragueneau, O. et al. A review of the Si cycle in the modern ocean: recent progress and missing gaps in the application of biogenic opal as a paleoproductivity proxy. Glob. Planet. Change 26, 317-365 (2000).

72. Iwasaki, S., Takahashi, K., Ogawa, Y., Uehara, S. \& Vogt, C. Alkaline leaching characteristics of biogenic opal in Eocene sediments from the central Arctic Ocean: a case study in the ACEX cores. J. Oceanogr. 70, 241-249 (2014).

73. Brown, E. T. in Micro-XRF Studies of Sediment Cores. Developments in Paleoenvironmental Research (eds. Croudace, I. W. \& Rothwell, R. G.) 267-277 (Springer, 2015).

74. Jimenez-Espejo, F. J. et al. Changes in detrital input, ventilation and productivity in the central Okhotsk Sea during the marine isotope stage $5 \mathrm{e}$, penultimate interglacial period. J. Asian Earth Sci. 156, 189-200 (2018).

75. Rothwell, R. G. \& Croudace, I. W. in Micro-XRF Studies of Sediment Cores. Developments in Paleoenvironmental Research (eds. Croudace, I. W. \& Rothwell, R. G.) 25-102 (Springer, 2015).

76. Agnihotri, R., Altabet, M. A., Herbert, T. D. \& Tierney, J. E. Subdecadally resolved paleoceanography of the Peru margin during the last two millennia. Geochem. Geophys. Geosyst. 9, Q05013 (2008).

77. Dickson, A. J., Leng, M. J., Maslin, M. A. \& Röhl, U. Oceanic, atmospheric and ice-sheet forcing of South East Atlantic Ocean productivity and South African monsoon intensity during MIS-12 to 10. Quat. Sci. Rev. 29, 3936-3947 (2010)

78. Martin-Puertas, C., Brauer, A., Dulski, P. \& Brademann, B. Testing climate-proxy stationarity throughout the Holocene: an example from the varved sediments of Lake Meerfelder Maar (Germany). Quat. Sci. Rev. 58 56-65 (2012).

79. Melles, M. et al. 2.8 Million years of arctic climate change from Lake El'gygytgyn, NE Russia. Science 337, 315-320 (2012).

80. Killick, R., Fearnhead, P. \& Eckley, I. A. Optimal detection of changepoints with a linear computational cost. J. Am. Stat. Assoc. 107, 1590-1598 (2012).

81. Lavielle, M. Using penalized contrasts for the change-point problem. Signal Process. 85, 1501-1510 (2005).

\section{Acknowledgements}

This research used samples and data provided by IODP expedition 318, sponsored by the US National Science Foundation (NSF) and participating countries under the management of the Consortium for Ocean Leadership, including the Australian and New
Zealand International Ocean Discovery Program Consortium. Funding was provided by Royal Society Te Apārangi Marsden Fund (18-VUW-089 to R.M.M. and 15-VUW-131 to N.A.N.B.) and the New Zealand Ministry of Business, Innovation and Employment through the Antarctic Science Platform (ANTA1801). Funding was also provided by the New Zealand Ministry of Business, Innovation and Employment Strategic Science Investment Fund (SSIF) through GNS Science (grant 540GCT32). We acknowledge funding from the Dumont d'Urville NZ-France Science and Technology Programme, MARICE project (Marine and Ice core reconstruction of East Antarctic sea ice variability over the past 2,000 years) (project nos. 45455NF and 19-VUW-047-DDU Catalyst Fund, RSNZ). J.E. and X.C. acknowledge funding by the ERC StG ICEPROXY (203441), the ANR CLIMICE and the FP7 Past4Future (243908) projects. F.J.J.-E. was funded by project 2018301092 (Spanish Research Council). C.E. and F.J.J.-E acknowledge funding by the Spanish Ministry of Science and Innovation (grant CTM2017-89711-C2-1-P), co-funded by the European Union through FEDER funds. C.R.R. was funded by a University of Otago research grant and a L'Oréal-UNESCO For Women in Science Australia and New Zealand Fellowship. The Natural Environment Research Council funded K.E.A. (CENTA PhD; NE/L002493/1) and J.B. (standard grant Ne/I00646X/1). Y.Y. was funded by the Japan Society for Promotion of Science (JSPS) grant no. JP20H00193. S.F.P. was supported by National Science Foundation grant OPP-0732796. R.B.D. was supported by National Science Foundation grants PLR-1644118 and OCE-1129101. The authors acknowledge the Norwegian Polar Institute's Quantarctica package, and the use of imagery from the NASA Worldview application (https://worldview.earthdata.nasa.gov/), part of the NASA Earth Observing System Data and Information System.

\section{Author contributions}

K.M.J., R.M.M. and N.A.N.B designed the study and wrote the paper with input from all authors. K.M.J., R.M.M. and H.J.H. analysed the X-ray CT data. R.M.M. and A.A. conducted the grain size analyses. J.E. produced the HBI data. F.J.J.-E. produced the XRF geochemical data. C.R.R. conducted the opal (\%BSi) measurements. M.Y. and Y.Y. analysed and provided the compound-specific ${ }^{14} \mathrm{C}$ ages. R.B.D. and C.E. were lead proponents of the ancillary IODP expedition 318 proposal to core IODP Site 1357. All authors contributed to the interpretations of data and finalization of the manuscript

\section{Competing interests}

The authors declare no competing interests.

\section{Additional information}

Extended data is available for this paper at https://doi.org/10.1038/s41561-021-00816-y.

Supplementary information The online version contains supplementary material available at https://doi.org/10.1038/s41561-021-00816-y.

Correspondence and requests for materials should be addressed to Katelyn M. Johnson.

Peer review information Nature Geoscience thanks Kaarina Weckström and the other, anonymous, reviewer(s) for their contribution to the peer review of this work. Primary Handling Editor(s): James Super.

Reprints and permissions information is available at www.nature.com/reprints. 


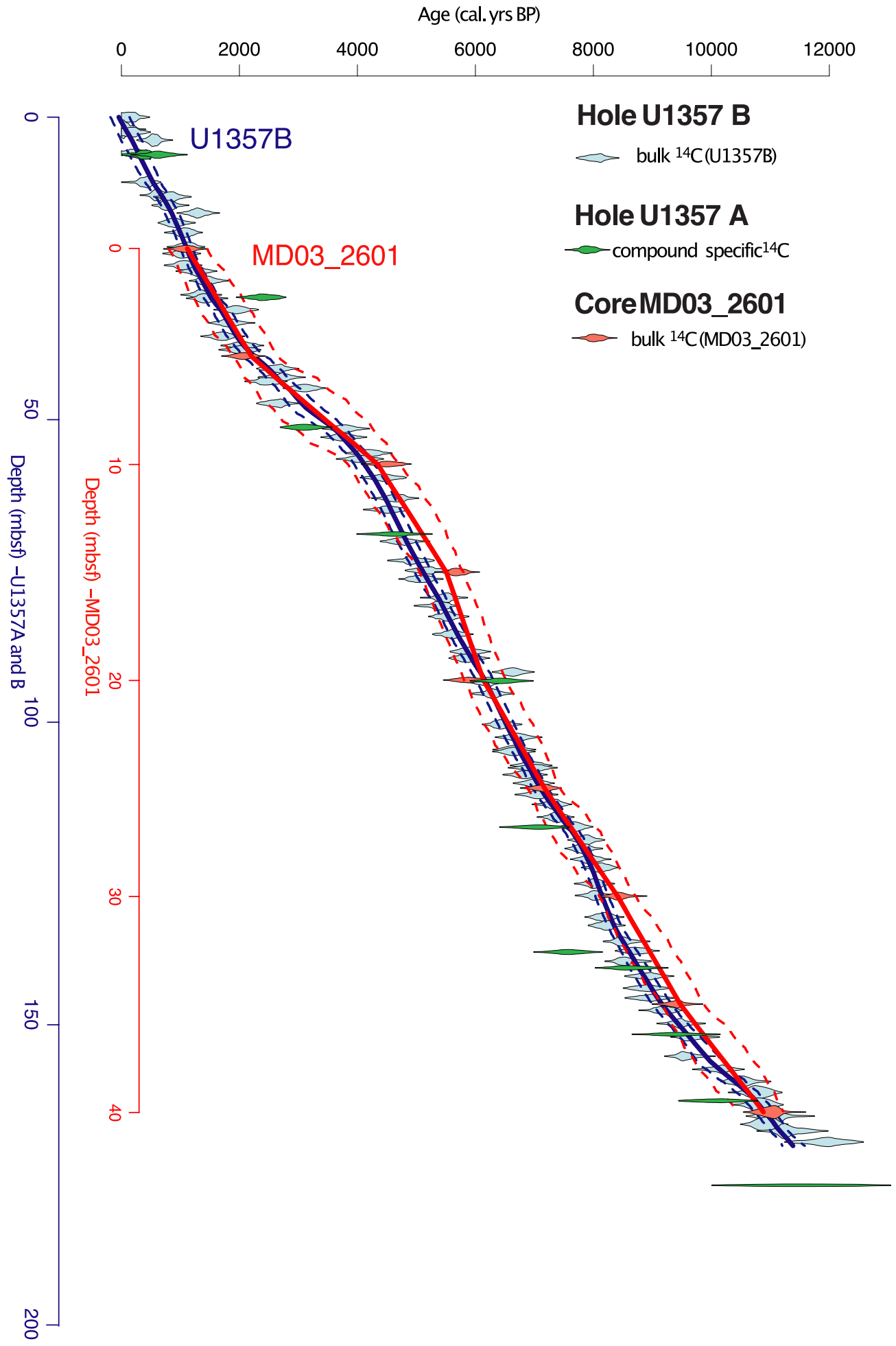

Extended Data Fig. 1 | Corrected and calibrated radiocarbon age models for U1357B and MD03-2601. Age Model for U1357B (blue symbols show calibrated and corrected ages, and blue line of calculated Bayesian age-depth curve, using BACON R package; dotted lines are 2 sigma uncertainty) and MD03-2601 (red symbols and lines as for U1357B) show that sediment advection is a regional signal as sedimentation rates covary. Compound specific ages from U1357A are shown in green with 2 sigma uncertainties. U1357B is a longer core with $87{ }^{14} \mathrm{C}$ dates, leading to a much higher resolution age model. U1357B also includes the last 1,000 years, which is lacking in MD03-2601. 

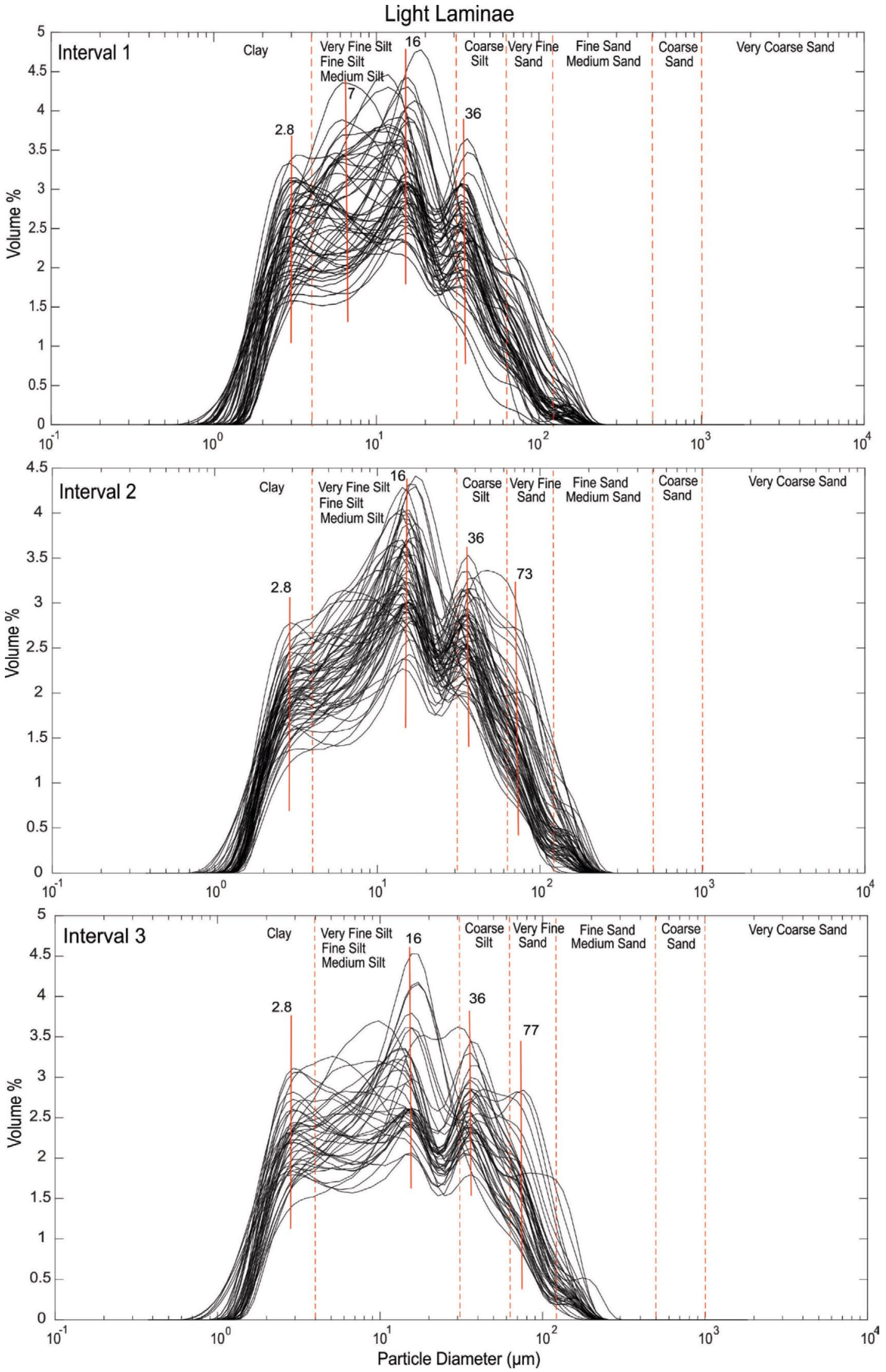

Extended Data Fig. 2 | Grain size analysis of light laminae. Light laminae in three intervals (Interval 1: 4.5 to present; Interval 2: 8-4.5 ka; Interval 3: 11.4-8 ka;) have a dominant silt-fine sand mode and are less than $125 \mu \mathrm{m}$. Sand percent provides a measure of this coarse silt to fine sand mode and is used as a proxy to capture the upper values of relative current strength. 

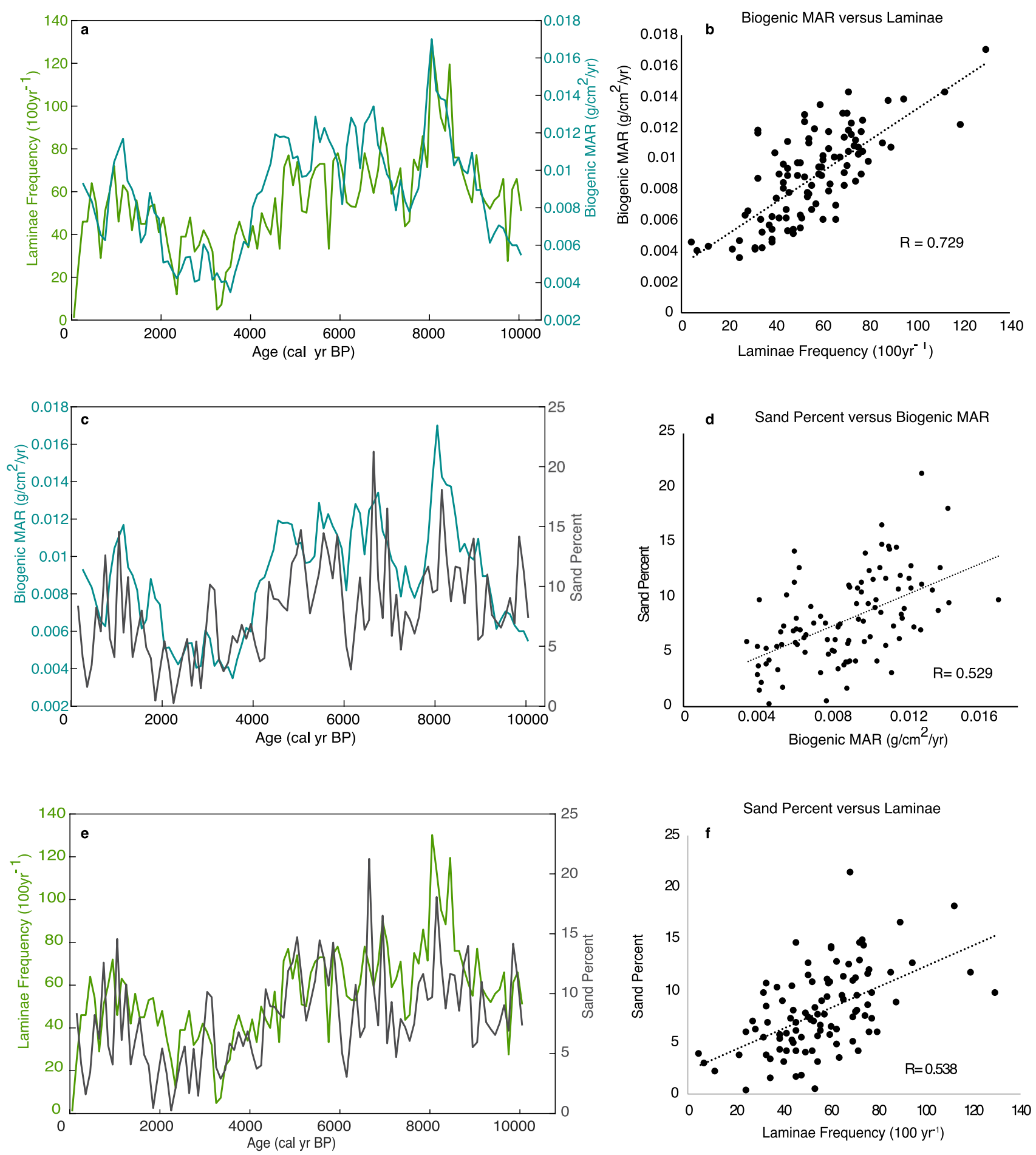

Extended Data Fig. 3 | Correlations of Adélie Drift Proxies. (a,b) Overlay plot and correlation between laminae counts (frequency of biological blooms) and biogenic mass accumulation rates (advection of biological material by wind driven current strength). (c,d) Overlay plot and correlation between sand percent (grain size proxy for wind driven current strength) and biogenic mass accumulation rates (advection of biological material by wind driven current strength). (d,e) Overlay plot and correlation between sand percent (grain size proxy for wind driven current strength) and laminae counts (frequency of biological blooms). 


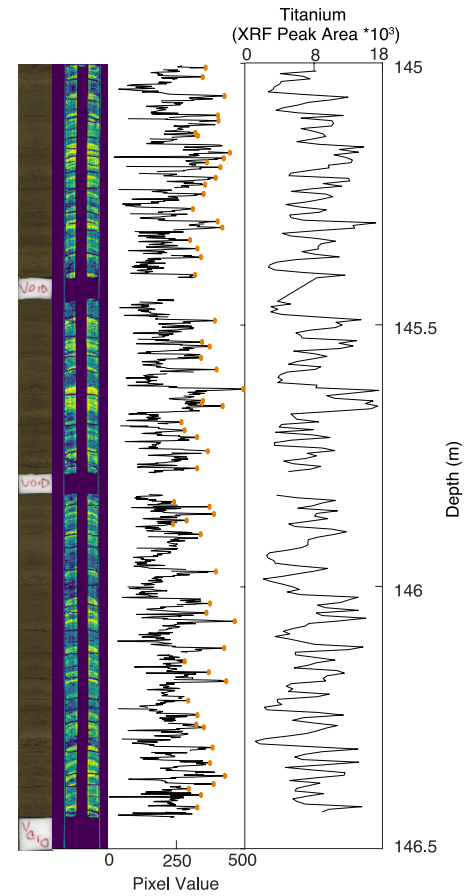

Extended Data Fig. 4 | Image Analysis example. From left to right: Line-scan core photo, CT image, raw greyscale curve with light laminae picks in orange, and XRF titanium data. The CT image visually enhances the laminations, and provides a sub-mm resolved greyscale curve that better captures the rapid shifts in sedimentation. Frequencies from the manually picked laminae (Fig. 3d) match those extracted from the greyscale curve (Fig. 4). 


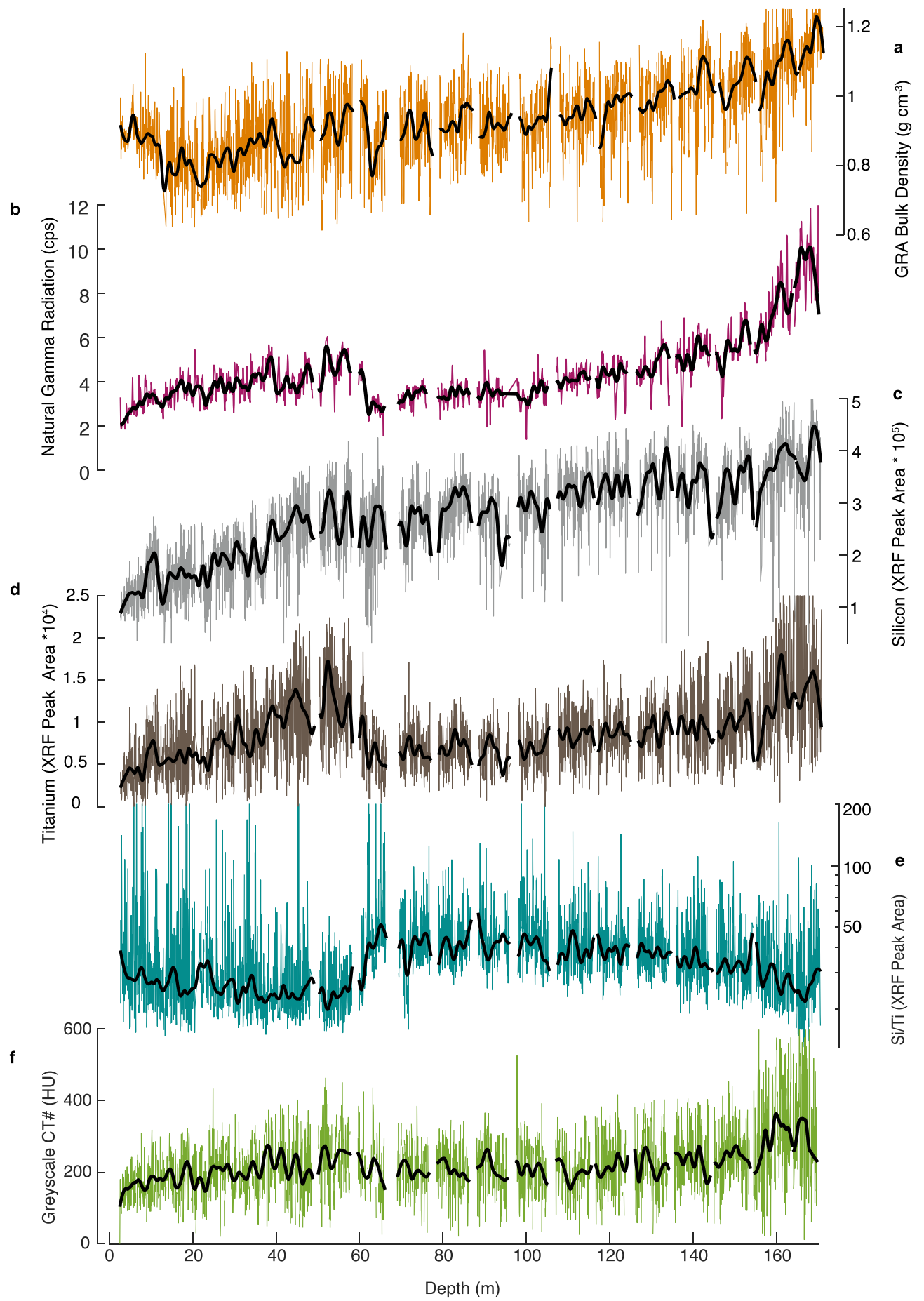

Extended Data Fig. 5 | Greyscale data in relation sedimentological changes at the site. Greyscale data compared to various sedimentological proxies of the core. (a) GRA Bulk Density (b) Natural Gamma Radiation (NGR) (c) XRF peak area of silicon (d) XRF peak area of titanium (e) XRF peak area of silicon/titanium ratio used to indicate long-term changes in biological productivity (f) Greyscale curve from the CT images. XRF, GRA Bulk Density, and Greyscale interpolated to $5 \mathrm{~cm}$. Black curves indicate a robust LOESS smoothing using $2 \%$ of the data points for all data sets. GRA Bulk Density and NGR data from ref. ${ }^{17}$. 
b

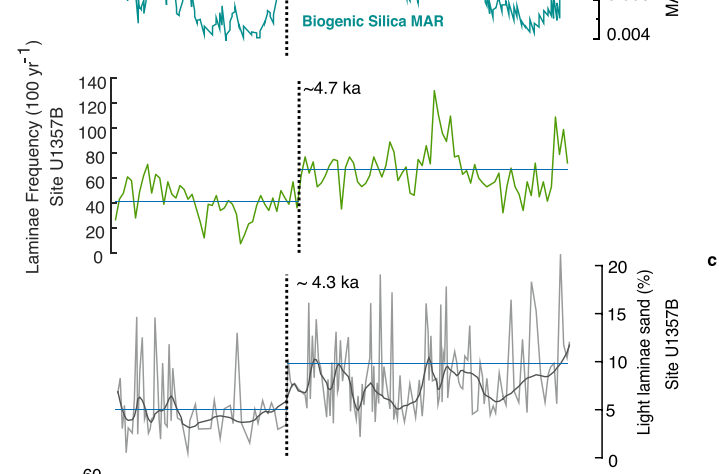

d

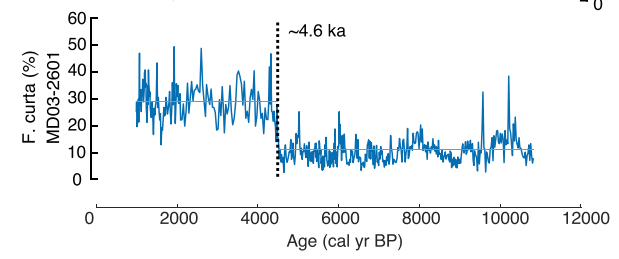

Extended Data Fig. 6 | Holocene Mean Changepoints. Calculation of shifts in the mean of various Holocene records using statistical changepoint analysis. This method identifies the point at which the mean of a timeseries changes most significantly by finding the point at which the total residual error from the mean of each section is minimized (ref. ${ }^{80,81}$ ). Shifts in Adélie Land proxies (a-d) occur between $\sim 4.3$ and $\sim 4.7 \mathrm{ka}$. 


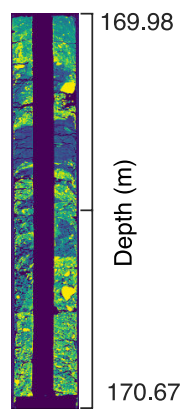

Extended Data Fig. 7 | IBRD in U1357B. Section 19H5 (169.98-170.67 m) from U1357B is the only portion of core with substantial IBRD. The top of this section is dated to $\sim 11.365 \mathrm{ka}$. 